\title{
Studies of alternaria black spot disease of pomegranate caused by Alternaria alternata in Punjab
}

\author{
Adesh Kumar, ${ }^{*}$ Tanjeet Singh Chahal, Mandeep Singh Hunjan ${ }^{1}$, Harminder Kaur ${ }^{1}$ and \\ Roomi Rawal $^{2}$
}

Punjab Agricultural University, Fruit Research Station, Jallowal- Lesriwal, Jalandhar-144303 (Punjab), INDIA

${ }^{1}$ Department of Plant Pathology, Punjab Agricultural University, Ludhiana-141004 (Punjab), INDIA

${ }^{2}$ Department of Entomology, Haryana Agricultural University, Hisar-125001 (Haryana), INDIA

*Corresponding author. E-mail: adeshfrs@gmail.com

Received: May 15, 2016; Revised received: September 26, 2016; Accepted: January 15, 2017

\begin{abstract}
Alternaria black spot of pomegranate caused by Alternaria alternata pose significant economic losses in India as it reduce the crop yield. Farm survey was undertaken at Punjab Agricultural University, Pomegranate Research Block, Fruit Research Station, Jallowal- Lesriwal Jalandhar during 2015. Among all the five cultivars highest disease incidence $(70 \%)$ and severity $(30 \%)$ was registered in cultivar Bhagwa. Twenty two isolates of A. alternata were recovered from infected fruits and clustered using UPGMA (unweighted pair group method with arithmetic averages) on the basis of disease score produced in five cultivars (Ganesh, Ruby, Bhagwa, Jyoti and Mridula). It was revealed that five isolates namely AL14, AL15, AL20, AL21 and AL22 were highly virulent on almost all the pomegranate cultivars. Two cultivars viz. Bhagwa and Mridula were found to be most susceptible as $45.45 \%$ isolates were found to be highly virulent on them. The in vitro antifungal effects of the six fungicides on mycelial growth were investigated. Based on the inhibition of mycelial growth, all the fungicides showed most toxic reaction with $50 \%$ effective concentrations $\left(E_{50}\right)$ of $<1 \mathrm{ppm}$. However, they varied in EC90 values. $10 \mathrm{ppm}$ cocentration of Tilt (azole group) showed $90 \%$ effective concentration $\left(E_{90}\right)$. Folicur also showed approximately same results as Tilt while $\mathrm{EC}_{90}$ value of Natio and SAAF was $<25 \mathrm{ppm}$ and $>20 \mathrm{ppm}$. However, two fungicides namely Dithane Z-78 and Bavistin showed less toxicity against Alternaria alternata as compared to other with $\mathrm{EC}_{90}$ value at concentrations $<50 \mathrm{ppm}$ and $>$ $25 \mathrm{ppm}$. Azole group fungicides (Tilt and Folicur) were found most effective to inhibit the pathogen growth.
\end{abstract}

Keywords: Alternaria black spot, Alternaria alternata, Cultivars, Fungicides and Pomegranate

\section{INTRODUCTION}

Pomegranate (Punica granatum L.) a high value fruit crop that cultivated worldwide with dominancy in Mediterranean countries like Spain, Morocco, Egypt, Iran, Afghanistan and Baluchistan since ancient times. Tropical and sub-tropical regions of the Indian sub-continent are the prominent areas under cultivation of this fruit crop. India plays a leading role in pomegranate production with contribution of nearly $50 \%$ of global pool. The total area under pomegranate is 132 thousand hectare with annual production of 1357 thousand MT in 2014-2015 (Anonymous, 2015).

A. alternata is an important plant pathogen that causes black spot disease with symptoms present on leaves, flowers, and young fruit of pomegranate (Pala et al., 2009; Holland et al., 2009). This disease is a major hurdle in quality production and high yield in the crop causing up to $15-80 \%$ losses in Karnataka including Bijapur, Bagalkot and Koppal districts (Archana and Jamadar, 2014).

A. alternata responsible for fruit rot was first reported in India by Madhukar and Reddy (1976) and subse- quently from USA and Mexico (Farr et al., 2007). In currently Alternaria black spot disease is reported in different part of the world such as Greece (Tziros et al. 2007), Israel (Ezra et al., 2010) and Spain (Berbegal et al., 2014). This pathogen belongs to omnipresent necrotrophic fungi group and have at least seven pathogenic variants of this fungus, each producing unique host-selective toxins (HSTs) and causing disease on specific host plants (Ito et al., 2004). In Punjab, this disease invariably appears every year in the pomegranate orchards causing significant yield and quality loss. For management of fungal plant pathogens, fungicides have important role to control plant disease. Fungicides inhibit the growth of the fungi under in vitro and in vivo condition (Archana and Jamadar, 2014; Nel et al., 2007). They have different mode of action to control the fungal growth. Mesta et al. (2011) used sterol demethylation inhibitors fungicides namely propiconazole and hexaconazole with conc $0.1 \%$ to control Alternaria blight of Sunflower. Azoxystrobin fungicides have potential to inhibit mitochondrial respiration and blocking the cytochrome bc1 complex can be used to control Alternaria solani pathogen causing 
Table 1. Disease severity response of Alternaria black spot disease on pomegranate (Punica granatum L.).

\begin{tabular}{lc}
\hline Response & Per cent Infection on fruit pericarp \\
\hline 0 & 0.00 \\
1 & Up to 1 \\
2 & $>1-10$ \\
3 & $>10-20$ \\
4 & $>20-40$ \\
5 & $>50$ \\
\hline
\end{tabular}

agent of potato early blight (Pasche et al., 2004). Realizing the importance of this disease, the present studies were initiated to isolate, identify and characterize the pathogen with respect to its aggressiveness and also evaluate different fungicides against $A$. alternata under in vitro condition.

\section{MATERIALS AND METHODS}

Isolation and identification of the pathogen: Symptomatic fruits were collected from Punjab Agricultural University, Pomegranate Research Block, Fruit Research Station, Jallowal- Lesriwal Jalandhar, Punjab in the month of June, 2015. Disease incidence was recorded by counting the number of infected fruits per plant. For disease severity, 20 fruits were selected randomly and scoring was done with help of 1-5 scale. After surface sterilization, the peel pieces were placed on potato dextrose agar separately and grown at $25{ }^{\circ} \mathrm{C}$ for 2-3 days. The growing fungal hyphal tips were transferred to PDA and grown for 4-5 days, and cultures were further purified by single spore isolation method. The morpho-logical characteristics of the conidia were analyzed using Leica microscope (DM 2000) at $100 \mathrm{X}$. Twenty two isolates of the Alternaria black spot pathogen were recovered and used for this study.

Pathological characterization and aggressiveness: All the twenty two isolates were grown individually on PDA medium and PDA-plugs, $5 \mathrm{~mm}$ in diameter, with actively grown mycelium were transferred on fruit wounds made by a scalpel on previously sterilized fruit surfaces. Full sized pomegranate fruits of all cultivars viz. Ganaesh, Ruby, Jyoti, Mridula and Bhagwa were inoculated with individual isolate (Tziros et al., 2007). After inoculation fruits were covered with plastic bags for 7- 10 days and moisture was maintained by hand sprayer (one spray daily up to symptom development) in plastic bags. The fruits inoculated with PDA medium only served as control. After inoculation, the plants
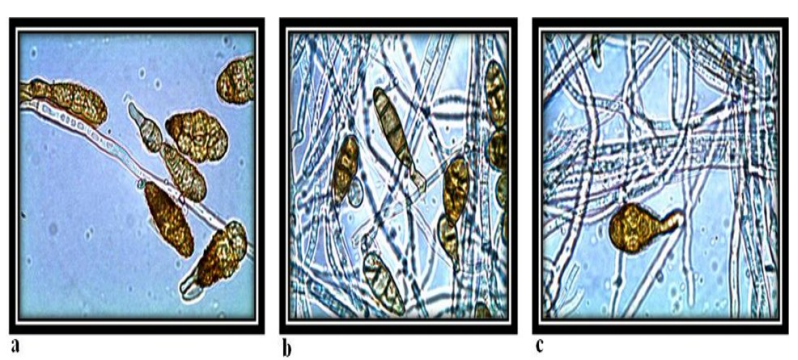

Fig. 1. Conidia of $A$. alternata with longitudinal and transverse septa (a-AL15, b-AL20 and c-AL21).

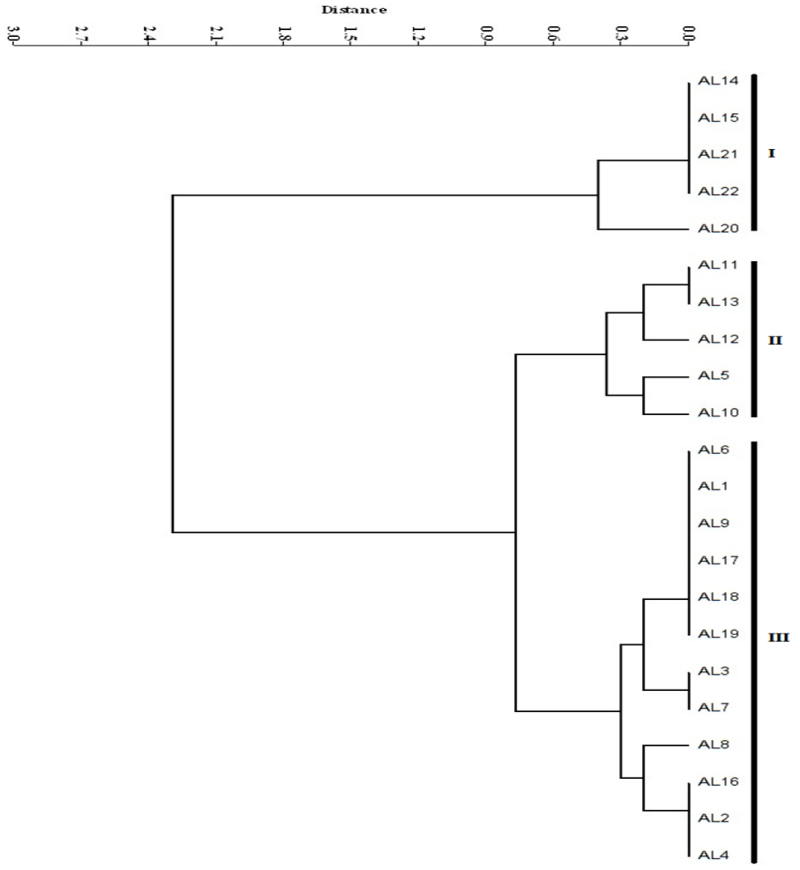

Fig. 2. Clustering of different isolates of A. alternata on the basis of virulence character.

were frequently irrigated to keep up high humidity and soil moisture which is vital for disease development. The disease symptoms were observed after 48-72 hrs of inoculation and final observations were recorded after 10 days. Disease severity was recorded on the basis of pathogen response and was divided into five categories (Table-1). The pathogen was re-isolated from the infected inoculated fruits and reconfirmed as A. alternata.

In vitro efficacy of different fungicides against A. alternate: Fungicides (Table 2) were evaluated to determine their 50\% effective concentration (EC50) and EC90 val-ues for the inhibition of mycelial

Table 2. Fungicides used in this study to control the growth of $A$. alternate.

\begin{tabular}{lllll}
\hline Fungicides & Chemical group & Active ingredient & Concentration (\%) & Formulation \\
\hline Folicur & Azole & Tebuconazole & 25.9 & EC \\
Tilt & Azole & Propiconazole & 25 & EC \\
Natio & Mixture of Azole and Strobilurin & Tebuconazole+ Trifloxystrobin & $50+25$ & WG \\
SAAF & Mixture of benzimidazole and & Carbendazim+ Mancozeb & $12+63$ & WP \\
& Carbamate & & 50 & WP \\
Bavistin & benzimidazole & Carbendazim & 70 & WP \\
Dithane Z-78 & Carbamate & zineb & & \\
\hline
\end{tabular}


Table 3. Disease incidence (DI) and disease severity (DS) of Alternaria black spot disease of pomegranate (Punica granatum L.).

\begin{tabular}{lcc}
\hline Cutivars & DI\% & DS\% \\
\hline Ruby & 10 & 3 \\
Ganesh & 50 & 25 \\
Jyoti & 56 & 27 \\
Bhagwa & 70 & 30 \\
Mridula & 40 & 14 \\
\hline
\end{tabular}

growth. To analyze the inhibi-tion of mycelial growth of A. alternata, five replicate PDA plates $(90 \mathrm{~mm}$ in diameter) con-taining the fungicides were prepared at concentrations of $1,10,20,25$ and 50ppm. The control plates contained only PDA medium. Individual agar disks (6 $\mathrm{mm}$ in diameter) were removed from the edge of an actively growing culture (AL 22) and placed at PDA plates that containing fungicides and incubated at $25^{\circ} \mathrm{C}$ for $4-5$ days. The mycelium growth of pathogen was measured by scale and compared with growth observed in control. The concentration of each fungicide causing $50 \%\left(\mathrm{EC}_{50}\right)$ or $90 \%\left(\mathrm{EC}_{90}\right)$ reduction in mycelial growth compared to the absence of the fungicide was estimated referring to Matheron and Porchas (2000) and based on the estimated values.

Statistical Analysis: The pathotypic similarity between the various isolates was generated using unweighted paired group mean averages using software programme PAST ver. 2.1.5.

\section{RESULTS AND DISCUSSION}

The Alternaria black spot disease incidence on cultivar Bhagwa, a popular variety was observed to be very high. At Fruit Research Station Jallowal, $70 \%$ of the plants showed symptoms of this disease with mean disease severity of $30 \%$ (Table-3). It was followed by Jyoti and Ganesh varieties where disease incidence was observed to be $56 \%$ and $50 \%$ respectively. In contrast disease incidence and severity of Alternaria

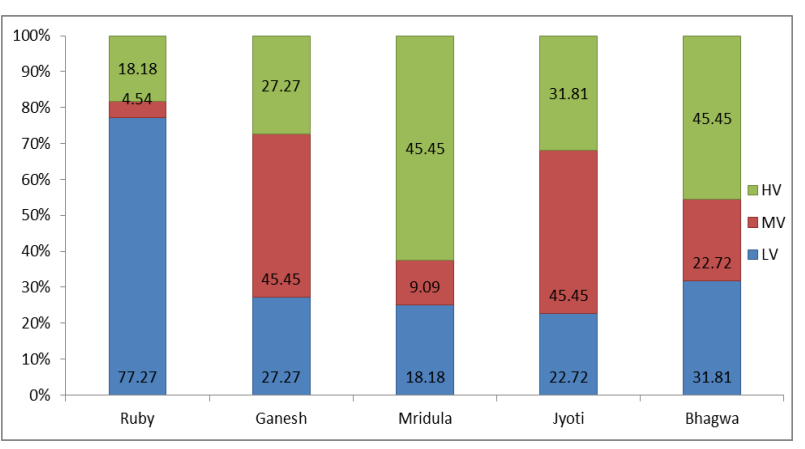

Fig. 3. Virulence frequency of twenty two isolates of A. alternata on five pomegranate cultivars.

black spot was low on Ruby and Mridula varieties (Table-3).

Isolation and identification of the pathogen: A total of twenty two isolates were recovered from infected fruit samples. All the isolates showed typical characters of $A$. alternata with Gray-to-black colonies. The pathogen conidiophores were short, septate, branched or unbranched, green to brown, obpyriform with conical or cylindrical beak (Simmons, 1967) (Fig. 1).

Pathological characterization and aggressiveness: Different response with respect to disease aggressiveness (number of disease spot on fruit) was observed within different isolates. Symptoms appeared 48-72 h later, followed by spreading on all fruit pericarp. The data presented in Fig. 2 shows the presence of significantly diverse virulence spectrum in A. alternata populations of Punjab. Disease response with respect to twenty two isolates of $A$. alternata clustered using UPGMA (Fig. 2). The data plotted in dendrogram (Fig.1) showed five isolates namely AL14, AL15, AL20, AL21 and AL22 to be clustered together and were classified in group I. These isolates were found to be highly virulent on almost all the cultivars tested producing the maximum mean disease score 4.92 (Table 4).

Table 4. Grouping of twenty two isolates of A. alternata on the basis of virulence reaction on five pomegranate cultivars.

\begin{tabular}{llcccc}
\hline Group & Name of Isolates & No. of Isolates & \multicolumn{2}{c}{ Disease score } & \multirow{2}{*}{ Remark } \\
\cline { 3 - 5 } & & & Mean & Range & \\
\hline I & AL14, AL15, AL20, AL21 and AL22 & 5 & 4.92 & $4.6-5$ & Highly Virulent \\
II & AL1, AL2, AL3, AL4, AL6, AL7, AL18, AL9, & 12 & 2.85 & $2.6-3.2$ & Moderately Virulent \\
& AL16, AL17, AL18, and AL19 & & & & \\
III & AL5, AL10, AL11, AL12 and AL13 & 5 & 2.08 & $1.8-2.4$ & Less Virulent \\
\hline
\end{tabular}

Table 5. Evaluation of different fungicides against A. alternata under in vitro condition.

\begin{tabular}{lcccccc}
\hline \multirow{2}{*}{ Fungicides } & \multicolumn{7}{c}{ Mycelial growth (mm) } \\
\cline { 2 - 7 } & $\mathbf{1}$ & $\mathbf{5}$ & $\mathbf{6}$ Concentration in ppm & $\mathbf{2 0}$ & $\mathbf{2 5}$ & $\mathbf{5 0}$ \\
\cline { 2 - 7 } & $20.4(0.23)$ & $18.4(0.24)$ & $16.2(0.53)$ & $11.8(0.23)$ & 0 & 0 \\
Natio & $24.8(0.53)$ & $17.2(0.26)$ & $9.4(0.23)$ & $8.2(0.93)$ & 0 & 0 \\
Folicur & $19.2(0.13)$ & $11.4(0.22)$ & $9(0.12)$ & 0 & 0 & 0 \\
Tilt & $41.6(0.33)$ & $23.6(0.42)$ & $18.4(0.43)$ & $13(0.29)$ & $9.2(0.53)$ & $4.6(0.83)$ \\
Bavistin & $28.4(0.22)$ & $19.6(0.22)$ & $17.2(0.73)$ & $15.4(0.28)$ & $12.8(0.23)$ & $8.6(0.33)$ \\
Z-78 & $39(0.63)$ & $23.4(0.32)$ & $17.8(0.53)$ & $12.4(0.27)$ & $8.6(0.25)$ & $6.2(0.93)$ \\
SAAF & &
\end{tabular}

Figures in parentheses are standard deviations from mean of five replications. 

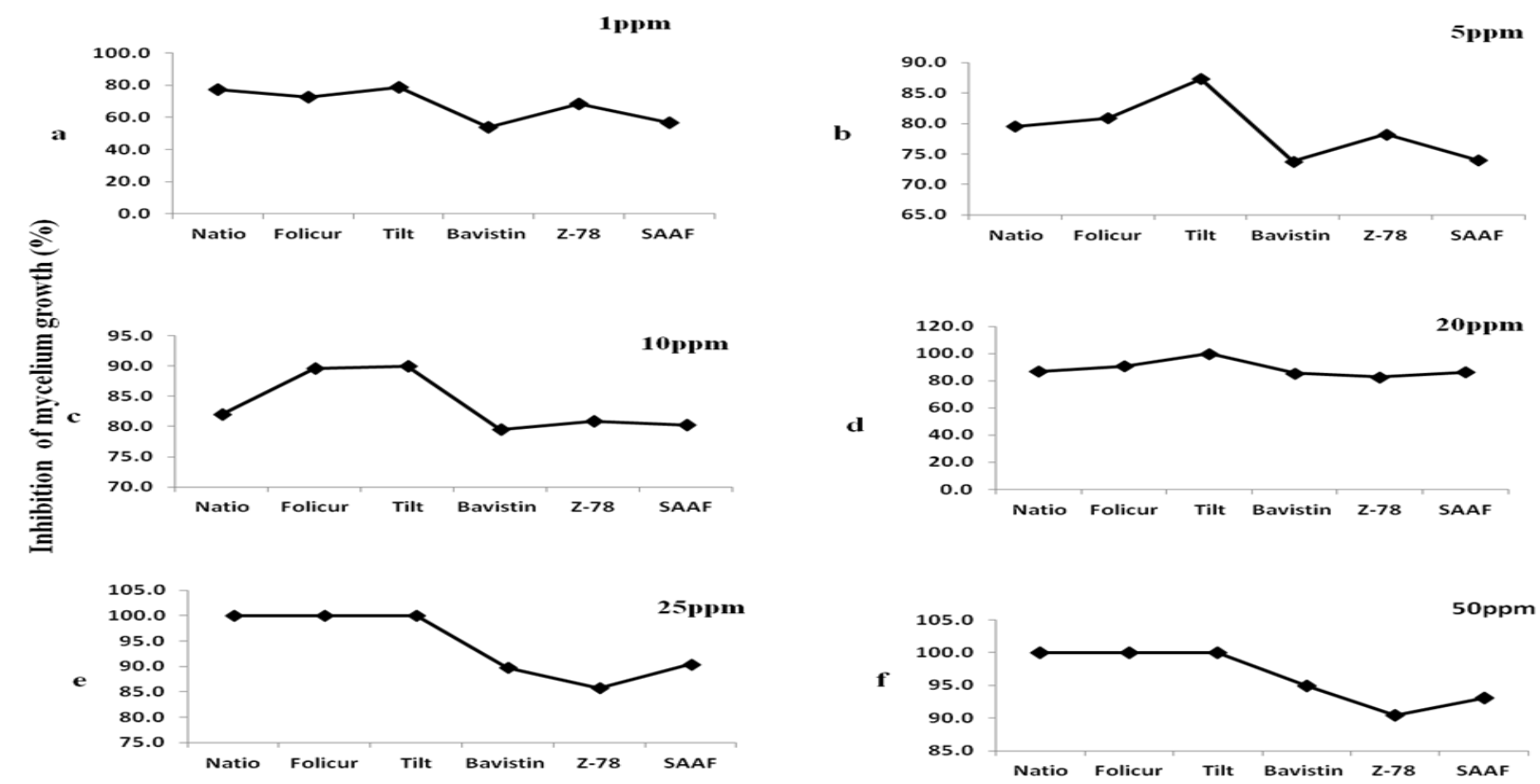

Fig. 4. Inhibition \% of A. alternata mycelium by different fungicides at different concentrations (a. 1, b. 5, c. 10, d. 20, e. 25 and f. 50ppm).

Twelve out of all the isolates showed disease score ranging from 2.6 to 3.2 with mean 2.85 and were classified as moderately virulent (Table 4 ). These isolates were unable to cover all the fruit with external symptoms, disease progress was observed only less than half fruit length from the point of inoculation. The lowest disease score ranged from 1.8-2.4 with mean 2.08, which was recorded in 5 isolates where the disease restricted only to point of inoculation (Table 4). Similarly, Gat et al. (2012) observed variability in disease severity among the isolates of $A$. alternata and classified them into four groups. Isolates that did not induce any visible symptoms were classified into virulence group. Isolates that caused mild, moderate, or severe symptoms were classified into virulence groups 1,2, and 3 respectively. Berbegal et al. (2014) inoculated fruit and leaves of pomegranate with $A$. alternata and disease symptom was observed after 10 and 3 days respectively.

Virulence frequency of $\boldsymbol{A}$. alternata isolates on five pomegranate cultivars: Currently meager work might be available regarding screening of pomegranate germplasm against this disease. In the present study
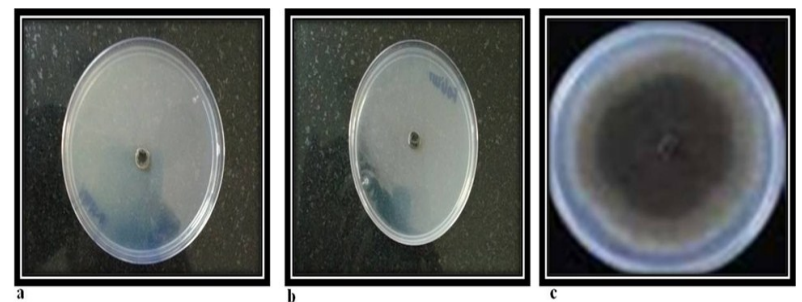

Fig. 5. Inhibition of A. alternata mycelium growth at 20ppm by Tilt (a), Folicur (b) and without chemical work as control (c) five pomegranate cultivars were screened (Fig. 3) which showed different reaction to Punjab population of $A$. alternata. Two cultivars i.e. Mridula and Bhagwa were found to be most susceptible as $45.45 \%$ isolates were found to be highly virulent on both. It was followed by Jyoti and Ganesh which were susceptible to 31.18 and $27.27 \%$ isolates respectively. However, Ruby was found to be comparatively less susceptible as only $18.18 \%$ isolates showed virulent reaction to Punjab population of $A$. alternata.

In vitro efficacy of different fungicides against A. alternate: The study assessed the effect of several fungicides viz. Folicur (tebuconazole), Tilt (propiconazole), Dithane Z-78, Natio, Bavistin and SAAF on pathogen growth inhibition (Table 5). The $\mathrm{EC}_{50} / \mathrm{EC}_{90}$ values for the six fungi-cides were determined and are shown in Table 6. The $\mathrm{EC}_{50}$ values of $A$. alternata for the six fungicides were $<1 \mathrm{ppm}$, all the fungicides reduced the fungi growth more than half at this concentration (Fig. 4 and Table 6). Two azole fungicides (Tilt and Folicur) were inhibited the mycelial growth of $A$. alternata most effectively at concentration of $10 \mathrm{ppm}$ com-pared to the others fungicides (Natio, Bavistin, Dithane Z-78 and SAAF) (Fig. 4 and $5)$. Azole fungicides are sterol demethylation inhibitors (DMIs) that inhibit the C-14 $\alpha$-demethylation of 24methylenedihydrolanosterol, a pre-cursor of ergosterol in fungi (Yin et al., 2009). Several field or in vitro studies have shown that DMI fungicides such as tebuconazole and propiconazole can control plant pathogenic fungi in different crops (Koller and Scheinpflug 1987; Islam et al. 2007; Ivić et al. 2011). The $\mathrm{EC}_{90}$ values of $A$. alternata for Natio and SAAF was $25 \mathrm{ppm}$ while for Z-78 and Bavistin fungicides was 50ppm. In 
Table 6. $\mathrm{EC}_{50}$ and $\mathrm{EC}_{90}$ values of mycelial growth of A. alternata for the six fungicides.

\begin{tabular}{lcc}
\hline Fungicides & EC $_{\mathbf{5 0}}$ & $\mathbf{E C}_{\mathbf{9 0}}$ \\
\hline Natio & $<1 \mathrm{ppm}$ & $<25 \mathrm{ppm}$ \\
Folicur & $<1 \mathrm{ppm}$ & $<20 \mathrm{ppm}$ \\
Tilt & $<1 \mathrm{ppm}$ & $10 \mathrm{ppm}$ \\
Bavistin & $<1 \mathrm{ppm}$ & $<50 \mathrm{ppm}$ \\
Z-78 & $<1 \mathrm{ppm}$ & $<50 \mathrm{ppm}$ \\
SAAF & $<1 \mathrm{ppm}$ & $<25 \mathrm{ppm}$ \\
\hline
\end{tabular}

this concentration growth of fungi reduced $>90 \%$ (Table 6) and (Fig. 4). Natio was the third best fungicide which reduced the mycelia growth efficiently with $25 \mathrm{ppm}$. Our study revealed that azole fungicides (Tilt and Folicur) were more effective at inhibiting the mycelial growth of $A$. alternata than other fungicides based on $\mathrm{EC}_{50}$ and $\mathrm{EC}_{90}$ values (Table 6). Similarly, Reuveni and Sheglov (2002) used azoles fungicides to control A. alternata pathogen in apple fruit crop. Archana and Jamadar (2014) also studied different fungicides against $A$. alternata and found that azole (propiconazole) reduced more disease as compared to strobilurin and other fungicides. Similar findings were also reported for other plant pathogenic fungi. Nel et al. (2007) evaluated different fungicides against Fusarium oxysporumf.sp. cubense causal agent of Fusarium wilt of banana and found two fungicides namely prochloraz and propiconazole was very effective to control disease at conc 1 and $5 \mu \mathrm{g} \mathrm{ml}^{-1}$, respectively. Similarly, Shin et al. (2014) control maize stalk rot disease pathogen Fusarium subglutinans and F. temperatum control by tebuconazole at conc $0.9 \mu \mathrm{g} /$ $\mathrm{ml}$. These studies can help to explore the effective chemicals under field condition to manage A. alternata.

\section{Conclusion}

The present study suggests that pathotypic diversity exist in Punjab isolates of Alternaria alternata, they are differentially aggressive on five pomegranate cultivars. It was observed that two cultivars namely Bhagwa and Mridula were found most susceptible, $45.45 \%$ isolates showed virulent reaction on both. However, Ruby cultivar was found less susceptible, only $18.18 \%$ isolates showed virulent reaction on this cultivar. The Azole fungicides (Tilt and Folicur) were found most effective to inhibit the $90 \%$ growth of the mycelium at $10 \mathrm{ppm}$ under in vitro condition. This group of chemical (Azole fungicides) will be further used in the field condition to manage Alternaria black spot disease of pomegranate in Punjab.

\section{REFERENCES}

Anonymous, (2015). Area and Production of pomegranate fruit in India. National horticulture mission online sources.

Archana, B.C. and Jamadar, M.M. (2014). Management of leaf spot and fruit spot /rot of pomegranate (Punica granatum L.) caused by Alternaria alternata (Fr.) Keis- sler. Karnataka J. Agric. Sci., 27:247-49.

Berbegal, M., López-Cortés, I., Salazar, D., Gramaje, D., Pérez-Sierra, A., García-Jiménez, J. and Armengol, J. (2014). First Report of Alternaria Black Spot of Pomegranate Caused by Alternaria alternatain Spain. Pl. Dis., 98:689

Ezra, D., Gat, T., Skovorodnikova, Y., Vardi, Y. and Kosto, I. (2010). First report of Alternaria black spot of pomegranate by Alternaria alternata in Israel. Aust. Plant Dis. Notes, 5:1-2

Farr, D. F., Rossman, A.Y., Palm, M. E. and McCray, E. B. (2007). Fungal Databases, Systematic Botany \& Mycology Laboratory, USDA: ARS. Retrieved February 5, 2007, from http://nt.ars-grin.gov/fungaldatabases.

Gat, T., Liarz, I. O., Skovorodnikova, Y., and Ezra, D, (2012). Characterization of Alternaria alternata causing black spot disease of pomegranate in Israel using a molecular marker. Plant Dis., 96:1513-18

Holland, D., Hatib, K. and Bar-Ya'akov, I. (2009). Pomegranate: botany, horticulture, breeding. Hortic. Rev., 35:127-92

Islam, S.S., Rahman, M. H., Hasan, M. J., Ashadusjaman, M. and Khatun, M.M. (2007). Efficacy of fungicidal seed treatment in Controlling Alternaria spp. in Radish Seed. Int. J. Sustain Crop Prod., 2:46-50

Ito, K., Tanaka, T., Hatta, R., Tamamoto, M., Akimitsu, K. and Tsuge, T. ( 2004). Dissection of the host range of the fungal plant pathogen Alternaria alternata by modification of secondary metabolism. Mol. Microbiol., 52:399-411

Ivić, D., Sever, Z. and Kuzmanovska, B. 2011. In vitro sensitivity of Fusarium graminearum, $F$. avenaceum and $F$. verticillioi-des to carbendazim, tebuconazole, flutriafol, metconazole and prochloraz. Pestic. Phytomed., $26: 35-42$

Koller, W. and Scheinpflug, H. (1987). Fungal resistance to sterol biosynthesis inhibitors: a new challenge. Plant Dis., 71:1066-74

Madhukar, J. and Reddy, S. M. (1976). Some new leaf spot diseases of pomegranate. Indian J. Mycol. Plant Path., 18:171-72

Matheron, M.E. and Porchas, M. (2000). Impact of azoxystrobin, dimethomorph, fluazinam, fosetyl-al, and metalaxyl on growth, sporulation, and zoospore cyst germination of three Phytophthora spp. Plant Dis., 84:454-58

Mesta, R.K., Benagi V. I., Kulkarni, S. and Basavarajappa, M.P. (2011). Management of Alternaria blight of sunflower through fungicides. Karnataka J. Agric. Sci., 24: 149-152

Nel, B., Steinber, C., Labuschagne, N. and Viljoen, A. (2007). Evaluation of fungicides and sterilants for potential applica-tion in the management of Fusarium wilt of banana. Crop Prot., 26:697-705

Pala, H., Tatli, A., Yilmaz, C. and Özgüven, A.I. (2009). Important disease of pomegranate fruit and control possibilities in Turkey. Acta. Hortic., 818:285-90

Pasche, J. S., Wharam, C. M. and Gudmestad, N. C. (2004). Shift in sensitivity of Alternaria solani in response to QoI fungicides. Plant Dis., 88:181-187

Reuveni, M.S.D. (2002). Effects of azoxystrobin, difenoconazole, polyoxin B (polar) and trifloxystrobin on germination and growth of Alternaria alternata and decay in red delicious apple fruit. Crop Protec., 21:951-55 
Adesh Kumar et al. / J. Appl. \& Nat. Sci. 9 (1): 156 -161 (2017)

Shin, J.H., Han, J.H., Lee, J.K. and Kim, K.S. (2014). Characterization of the maize stalk rot pathogens Fusarium subglutinans and $F$. temperatum and the effect of fungicides on their mycelial growth and colony formation. Plant Pathol. J., 30:397-406

Simmons, E.G. (1967). Typification of Alternaria, Stemphylium and Ulocladium. Mycologia, 59:67-92
Tziros, G.T., Lagopodi, A.L. and Tzavella-Klonari, K. (2007). Alternaria alternata fruit rot of pomegranate (Punica granatum) in Greece. New Dis. Rep., 15:14

Yin, Y., Liu, X., Li, B. and Ma, Z. (2009). Characterization of sterol demethylation inhibitor-resistant isolates of Fusarium asi-aticum and $F$. graminearum collected from wheat in China. Phytopathology, 99:487-497 